\title{
Intrinsic Viscosity-Molecular Weight Relationships in Copolyphosphates
}

\author{
H. N. Bhargava, ${ }^{*}$ C. B. Sharma, ${ }^{* *}$ and Rita Rani Srivastava \\ Department of Chemistry, Gorakhpur University, \\ Gorakhpur 273001, India
}

(Received December 26, 1985)

\begin{abstract}
A number of samples of sodium potassium $(\mathrm{Na}: \mathrm{K}=9: 1$ to $3: 7)$ and lithium potassium ( $\mathrm{Li}: \mathrm{K}=9: 1$ to $5: 5$ ) copolyphosphates were prepared and characterized. Their numberaverage molecular weights were determined by end-group titration and intrinsic viscosities were determined in $0.035 \mathrm{~N} \mathrm{NaBr}$ solution. Intrinsic viscosity-molecular weight relationships according to the Mark-Houwink equation were established for each series of compounds. A highly interesting feature of the results obtained was a decrease in the value of the constant $a$ with an increase in the mole fraction of potassium in the copolyphosphates. This is a remarkable demonstration of the dependence of $a$ on the degree of solvation; the solubilities of both kinds of copolyphosphates were found to decrease with an increase in the proportion of potassium.
\end{abstract}

KEY WORDS Sodium Potassium Copolyphosphates / Lithium Potassium Copolyphosphates / Intrinsic Viscosity / Molecular Weight / MarkHouwink Equation /

The long chain polyphosphates have been prepared and characterized by a number of workers over the last several decades. ${ }^{1-3}$ The techniques generally employed for determining their molecular weights include light scattering, ${ }^{4,5}$ end-group titration, ${ }^{6,7}$ and viscosity. ${ }^{4,7}$ Bhargava et al. ${ }^{5,7,8}$ have used all these techniques in a number of cases involving simple polyphosphates and Mehrotra et $a l .^{9}$ used the technique of end-group titration and viscosity in the case of compounds which could be termed 'copolyphosphates.' These are counter cation copolymers containing two kinds of cations attached to a polyphosphate chain -P-O-P-O-P-O, etc. Mehrotra et al., ${ }^{9}$ however, simply used the intrinsic viscosity [ $\eta$ ]-weight-average molecular weight $\left(M_{w}\right)$ relationship given by Strauss et al. ${ }^{4}$ for sodium polyphosphates without realizing that it could not hold good in the case of other poly- and copolyphosphates. In the present work $[\eta]-M_{n}$ relationships were obtained for a number of copolyphosphates having two cations. One series of compounds had sodium and potassium in molar ratios varying from $9: 1$ to $3: 7$ and another series had lithium and potassium in molar ratios $9: 1$ to $5: 5$. While $\mathrm{NaPO}_{3}$ and $\mathrm{KPO}_{3}$ units made up the former copolyphosphates, $\mathrm{LiPO}_{3}$ and $\mathrm{KPO}_{3}$ units were interlinked in the latter ones.

\section{EXPERIMENTAL}

\section{Materials and Methods}

(i) Preparation of Sodium-Potassium Copolyphosphates $(\mathrm{NaKPP}){ }^{* 1}$ Both $\mathrm{NaH}_{2} \mathrm{PO}_{4}$

* To whom lcorrespondence should be sent.

** Present address: Chemistry Department, Jahanabad College, Jahanabad, Bihar, India.

*1 The abbreviation NaK PP is used throughout this paper to describe compounds having sodium and potassium cations attached to the polyphosphate chain. 
and $\mathrm{KH}_{2} \mathrm{PO}_{4}$ polymerize on heating at temperatures higher than $400^{\circ} \mathrm{C}$.<smiles>[M]OP(=O)(O)[I+]O</smiles>

Orthophosphate Orthophosphate<smiles>[M]OP(=O)(O)OP(=O)(O)O</smiles>

Pyro- or Diphosphate

The condensation polymerization reaction ultimately leads to the formation of a high polymer.<smiles></smiles>

This can be written as $\mathrm{H}\left(\mathrm{MPO}_{3}\right)_{n} \mathrm{OH}$ or simply as $\left(\mathrm{MPO}_{3}\right)_{n} \cdot \mathrm{M}^{+}$represents monovalent cation.

In all the cases the chemicals used were of analytical grade obtained from reputed firms.

A reaction mixture of sodium dihydrogen orthophosphate and potassium dihydrogen orthophosphate required, taken in different molar ratios ranging from $9: 1$ to $3: 7$, was mixed thoroughly and placed in a platinum dish. The whole thing was heated in a Gallenkamp Muffle Furnace for a desired duration of time at a fixed temperature in the range of $700-850^{\circ} \mathrm{C}$. A clear molten liquid was obtained after heating the mixture, which was quickly quenched by pouring on cool surface of a stainless steel plate and quickly pressing another on it. Clear glassy products were obtained. They were powdered, dried in an oven at $100^{\circ} \mathrm{C}$, placed in a sample tube, and stored in a desiccator. All the glassy products were transparent and colourless and were easily soluble in water.

(ii) Preparation of Lithium-Potassium Copolyphosphates $\left(\right.$ LiKPP). ${ }^{* 2}$ For preparing LiKPP samples a reaction mixture of lithium carbonate, potassium dihydrogen orthophosphate and diammonium hydrogen phosphate, required in different $\mathrm{Li}: \mathrm{K}$ molar ratios, ranging from 9:1 to 5:5 was taken in a platinum dish and mixed well with the help of a glass stirrer. A set of five to six samples with similar $\mathrm{Li}: \mathrm{K}$ ratios were prepared. In every case the mixture was first heated gradually in an oven at a temperature of 150 $200^{\circ} \mathrm{C}$, taking care that the material does not spurt out in the initial stages when frothing takes place due to brisk evolution of ammonia, carbon dioxide and water vapour. After the frothing subsided the crucible was placed in a Gallenkamp Muffle Furnace, already heated to the desired temperature in the range $700-900^{\circ} \mathrm{C}$ for desired durations of time. The muffle furnace was capable of maintaining temperature within $\pm 10^{\circ} \mathrm{C}$.

The chemical reaction leading to the formation of lithium potassium copolyphosphate can be represented as follows:

$$
\begin{gathered}
x \mathrm{KH}_{2} \mathrm{PO}_{4}+\frac{1-x}{2} \mathrm{Li}_{2} \mathrm{CO}_{3} \\
+(1-x)\left(\mathrm{NH}_{4}\right)_{2} \mathrm{HPO}_{4} \longrightarrow \\
1 / n\left[K_{x} \mathrm{Li}_{(1-x)} \mathrm{PO}_{3}\right]_{n}+2(1-x) \mathrm{NH}_{3} \\
\quad+\frac{(3-x)}{2} \mathrm{H}_{2} \mathrm{O}+\frac{(1-x)}{2} \mathrm{CO}_{2}
\end{gathered}
$$

The products were all obtained in the form of clear molten liquids which, after heating for various durations of time, were chilled between two stainless steel plates in contact with ice-cooled water. The temperature of preparation and the time during which the mixture was kept in the muffle furnace are given in Table II. In all the cases the glassy product obtained on quenching was dried in an oven at $100^{\circ} \mathrm{C}$, powdered, placed in a sample tube and

*2 The abbreviation LiKPP will be used throughout this paper to describe compounds having lithium and potassium cations attached to the polyphosphate chain. 


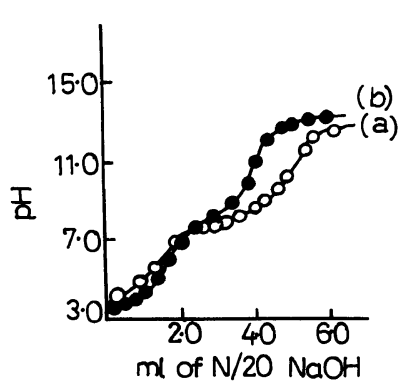

Figure 1. Typical titration curves for samples of copolyphosphates. (a) sample No. 1, Table I; (b) sample No. 26, Table I.

stored in a desiccator.

(iii) Determination of End-Group Molecular Weights. The $\mathrm{pH}$ was measured in all titrations by a glass electrode and a calomel half cell, a model 335 digital Systronics $\mathrm{pH}$-meter with an accuracy of \pm 0.01 being employed. Carbonate free $0.1 \mathrm{~N} \mathrm{NaOH}$ solution was used as a base. Titrations were carried out as quickly as possible to avoid contamination with atmospheric carbon dioxide. The solution was also stirred continuously with the help of a magnetic stirrer while adding alkali from a microburette.

In the case of NaKPP samples, a $1 \%$ solution was prepared in conductivity water. Since the $\mathrm{pH}$ of the freshly prepared solutions ranged from 6.0 to 7.0 , this solution was acidified to bring the $\mathrm{pH}$ to between 3.0 to 4.0. In each case $25 \mathrm{ml}$ of a $1 \%$ solution of the copolyphosphate in question was titrated against the base up to a $\mathrm{pH}$ of about 11.0. Two typical plots are given in Figure 1.

The determination of end-group molecular weight was based on the fact that there is one weak acid hydroxyl group at each end of the polymer chain, all other hydroxyl groups are strongly acidic. ${ }^{1}$

The weak acid groups titrate in the $\mathrm{pH}$ interval, between two points of inflexion (at pH 5 and 9). The number average molecular weight $M_{n}$ is given by ${ }^{6,7}$

$$
M_{n}=\frac{20000 w}{a}
$$

where $w$ is the weight of the copolyphosphate sample in gram and $a$ is the volume of $0.1 \mathrm{~N}$ $\mathrm{NaOH}$ in $\mathrm{cm}^{3}$ needed for titration between the two points of inflexion in a curve obtained by plotting $\mathrm{pH}$ against the volume of alkali added.

In the case of $\operatorname{LiK} P P$ samples the end-group molecular weight was determined by a method similar to that described by Greenfield and Clift. ${ }^{10}$ A freshly prepared $2 \%$ solution of the copolyphosphate in conductivity water was taken. A $25 \mathrm{ml}$ aliquot was diluted to $100 \mathrm{ml}$ and the $\mathrm{pH}$ adjusted to about 3.0 by adding drop by drop $1 N$ hydrochloric acid. It was then titrated between $\mathrm{pH} 4.5$ and 9.5 with $0.1 N$ sodium hydroxide solution $\left(V_{1}\right)$.

A $10 \mathrm{ml}$ aliquot was hydrolyzed by boiling on a sand bath with $25 \mathrm{ml}$ of $3 N$ nitric acid for at least $30 \mathrm{~min}$. It was then partially neutralized to $\mathrm{pH} 2-3$ with approximately $3 \mathrm{~N}$ sodium hydroxide solution and finally titrated between $\mathrm{pH} 4.5$ and 9.5 with $0.1 \mathrm{~N}$ sodium hydroxide solution $\left(V_{2}\right)$.

The number-average chain length $\bar{n}$ was calculated by using the formula

$$
\bar{n}=\frac{5 V_{2}}{V_{1}}
$$

By multiplying this number-average chain length with formula weight of the $\operatorname{LiK} P P$ samples, the number-average molecular weight was obtained.

(iv) Determination of Intrinsic Viscosity. The samples of copolyphosphates were dissolved in $0.035 \mathrm{~N} \mathrm{NaBr}$ and kept for $24 \mathrm{~h}$ for attaining stability. ${ }^{1,2}$ Their viscosities were then measured by using a Tuan-Fuoss viscometer ${ }^{11}$ with a flow time of about $120 \mathrm{~s}$. The intrinsic viscosities were determined in the usual way by plotting reduced viscosity $\left(\eta_{\text {sp }} / c\right)$ against concentration $(c)$ and extrapolating the former to zero concentration. A typical plot is shown in Figure 2 for a LiK $P P$ sample. Similar plots were obtained in all other cases.

When intrinsic viscosities are used for 


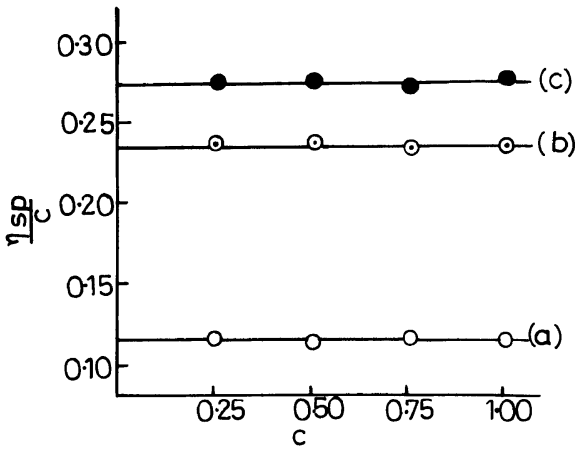

Figure 2. Reduced viscosity-concentration curves for samples of $\mathrm{LiK} P P$ in $0.035 \mathrm{~N} \mathrm{NaBr}$. (a) sample No. 1; $M_{n}=4180$ (Table II) (O); (b) sample No. $10 ; M_{n}=6360$ (Table II) ( $\odot$ ); (c) sample No. $18 ; M_{n}=9550$ (Table II) (O).

determining molecular weights one gets the weight-average or the number-average depending on the kind of average used for calibration as far as the heterogeneities of working and reference samples are approximately the same. According to the well-known MarkHouwink relationship:

$$
[\eta]=K M^{a}
$$

where $[\eta]$ is the intrinsic viscosity, $M$ is the molecular weight, and $K$ and $a$ are constants characteristic of the polymer.

Since a large number of samples of known end-group (number-average) molecular weights were available, the values of $K$ and $a$ could be easily obtained by plotting $\log [\eta]$ against $\log \mathbf{M}$.

\section{RESULTS AND DISCUSSION}

Molecular Weights and Intrinsic ViscosityMolecular Weight Relationships

Data giving the conditions of preparation of the copolyphosphates, their number-average molecular weights, and intrinsic viscosities in $0.035 N \mathrm{NaBr}$ solution are given in Tables I and II. The values of molecular weight were found to lie in the range $4000-9000$ in the case of NaKPP samples, while in the case
Table I. Relevant data for samples of sodium potassium copolyphosphates. Duration of heating before quenching was $3 \mathrm{~h}$ in each case

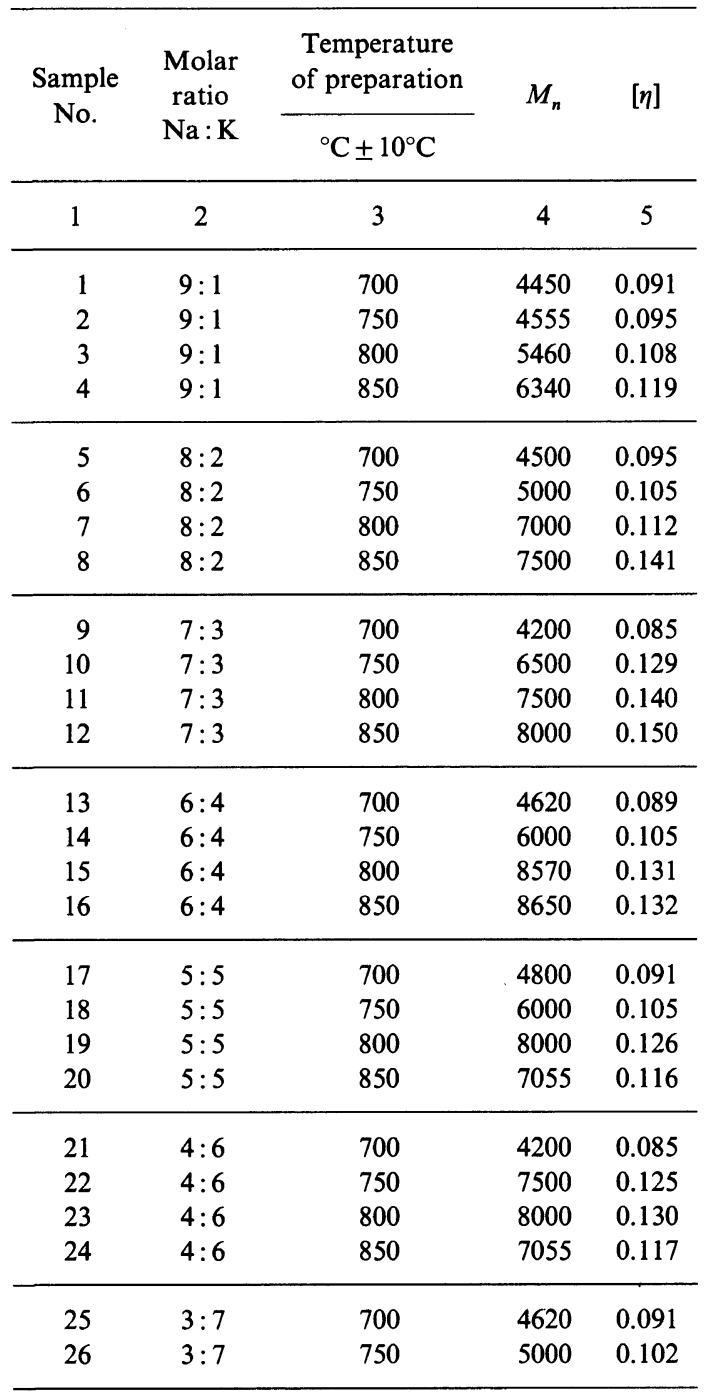

of LiKPP the molecular weights ranged from $4000-10000$. In both the cases, an increase in the temperature of preparation usually led to an increase in molecular weight.

The $\log [\eta]-\log M_{n}$ plots were drawn and on the basis of these plots the relationships between intrinsic viscosities and molecular weights as given in Tables III and IV could be calculated. 
Table II. Relevant data for samples of lithium potassium copolyphosphate

\begin{tabular}{|c|c|c|c|c|c|}
\hline \multirow[t]{2}{*}{$\begin{array}{c}\text { Sample } \\
\text { No. }\end{array}$} & \multirow{2}{*}{$\begin{array}{c}\text { Molar } \\
\text { ratio } \\
\mathrm{Li}: \mathrm{K}\end{array}$} & \multirow{2}{*}{$\frac{\begin{array}{c}\text { Temperature } \\
\text { of preparation }\end{array}}{{ }^{\circ} \mathrm{C} \pm 10^{\circ} \mathrm{C}}$} & \multirow{2}{*}{$\begin{array}{c}\begin{array}{c}\text { Duration } \\
\text { of heating } \\
\text { before }\end{array} \\
\text { quenching } \\
\frac{\mathrm{h}}{}\end{array}$} & \multirow[t]{2}{*}{$M_{n}$} & \multirow[t]{2}{*}[\eta]{} \\
\hline & & & & & \\
\hline 1 & 2 & 3 & 4 & 5 & 6 \\
\hline 1 & $9: 1$ & 700 & 3 & 4180 & 0.115 \\
\hline 2 & $9: 1$ & 700 & 6 & 6330 & 0.200 \\
\hline 3 & $9: 1$ & 800 & 3 & 6630 & 0.200 \\
\hline 4 & $9: 1$ & 800 & 6 & 6710 & 0.250 \\
\hline 5 & $9: 1$ & 900 & 3 & 6790 & 0.260 \\
\hline 6 & $9: 1$ & 900 & 6 & 9000 & 0.265 \\
\hline 7 & $8: 2$ & 700 & 3 & 4450 & 0.155 \\
\hline 8 & $8: 2$ & 700 & 6 & 4800 & 0.155 \\
\hline 9 & $8: 2$ & 800 & 3 & 6220 & 0.175 \\
\hline 10 & $8: 2$ & 800 & 6 & 6360 & 0.235 \\
\hline 11 & $8: 2$ & 900 & 3 & 6580 & 0.245 \\
\hline 12 & $8: 2$ & 900 & 6 & 8370 & 0.260 \\
\hline 13 & $7: 3$ & 700 & 3 & 4650 & 0.125 \\
\hline 14 & $7: 3$ & 700 & 6 & 5270 & 0.160 \\
\hline 15 & $7: 3$ & 800 & 3 & 6220 & 0.205 \\
\hline 16 & $7: 3$ & 800 & 6 & 9150 & 0.230 \\
\hline 17 & $7: 3$ & 900 & 3 & 9160 & 0.250 \\
\hline 18 & $7: 3$ & 900 & 6 & 9550 & 0.275 \\
\hline 19 & $6: 4$ & 700 & 3 & 4650 & 0.150 \\
\hline 20 & $6: 4$ & 700 & 6 & 4890 & 0.155 \\
\hline 21 & $6: 4$ & 800 & 3 & 4960 & 0.170 \\
\hline 22 & $6: 4$ & 800 & 6 & 8090 & 0.215 \\
\hline 23 & $6: 4$ & 900 & 3 & 8630 & 0.260 \\
\hline 24 & $5: 5$ & 700 & 3 & 5190 & 0.130 \\
\hline 25 & $5: 5$ & 700 & 6 & 5560 & 0.145 \\
\hline 26 & $5: 5$ & 800 & 3 & 6350 & 0.155 \\
\hline 27 & $5: 5$ & 800 & 6 & 7590 & 0.190 \\
\hline 28 & $5: 5$ & 900 & 3 & 7790 & 0.190 \\
\hline 29 & $5: 5$ & 900 & 6 & 9550 & 0.200 \\
\hline
\end{tabular}

In NaKPP samples dissolved in $0.035 \mathrm{~N}$ $\mathrm{NaBr}$ the value of ' $a$ ' lies between 0.50 to 0.93 . In all LiKPP samples the values of ' $a$ ' in salt solution media have been found to lie between 0.74 to 1.17 . The value of ' $a$ ' $=1.17$ is higher than that obtained for sodium polyphosphates $(a=1)$.

The value of $a$ is known to indicate how
Table III. Intrinsic viscosity-molecular weight relationships for sodium-potassium copolyphosphates

\begin{tabular}{ccc}
\hline $\begin{array}{c}\text { Sample } \\
\text { No. }\end{array}$ & $\begin{array}{c}\text { Molar ratio } \\
\text { Na:K }\end{array}$ & Relationship \\
\hline 1 & $9: 1$ & {$[\eta]=3.6 \times 10^{-5} M_{n}^{0.93}$} \\
2 & $8: 2$ & {$[\eta]=1.1 \times 10^{-4} M_{n}^{0.81}$} \\
3 & $7: 3$ & {$[\eta]=1.2 \times 10^{-4} M_{n}^{0.80}$} \\
4 & $6: 4$ & {$[\eta]=5.7 \times 10^{-4} M_{n}^{0.60}$} \\
5 & $5: 5$ & {$[\eta]=7.3 \times 10^{-4} M_{n}^{0.57}$} \\
6 & $4: 6$ & {$[\eta]=1.5 \times 10^{-3} M_{n}^{0.50}$} \\
\hline
\end{tabular}

Table IV. Intrinsic viscosity-molecular weight relationships for lithium-potassium copolyphosphates

\begin{tabular}{ccc}
\hline $\begin{array}{c}\text { Sample } \\
\text { No. }\end{array}$ & $\begin{array}{c}\text { Molar ratio } \\
\text { Li }: \text { K }\end{array}$ & Relationship \\
\hline 1 & $9: 1$ & {$[\eta]=7.3 \times 10^{-7} M_{n}^{1.17}$} \\
2 & $8: 2$ & {$[\eta]=6.3 \times 10^{-6} M_{n}^{0.93}$} \\
3 & $7: 3$ & {$[\eta]=7.3 \times 10^{-5} M_{n}^{0.89}$} \\
4 & $6: 4$ & {$[\eta]=2.7 \times 10^{-4} M_{n}^{0.75}$} \\
5 & $5: 5$ & {$[\eta]=2.5 \times 10^{-4} M_{n}^{0.74}$} \\
\hline
\end{tabular}

good or bad the solvent is for a particular polymer-solvent system at a particular temperature. ${ }^{12}$ In a theta-solvent in which the solubility is supposed to be minimum and there is little interaction between the solute and the solvent the value of $a$ approaches 0.5 . In all other cases its value lies above 0.5 but, particularly in the case of neutral polymers, the maximum value approaches a limit of $0.8 .^{12,13}$ However, in the case of polyelectrolytes this limit is quite often exceeded. ${ }^{14}$ In the case of NaKPP samples the solubility has been found to decrease with increase in the proportion of potassium and the concentration of salt solution used as $\theta$-solvent is also found to decrease. ${ }^{15}$ Similarly, in the case of LiKPP samples also the solubility decreases with increase in the proportion of potassium and the concentration of salt solution used as $\theta$ solvent also decreases with decrease in solubility. ${ }^{16}$

The dependence of ' $a$ ' on degree of solvation is beautifully illustrated in the plots of mole 


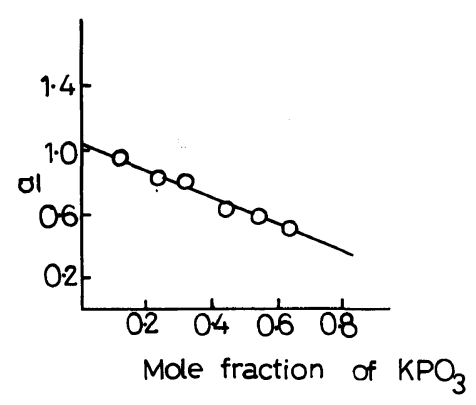

Figure 3. Plot of $a$ against mole fraction of $\mathrm{KPO}_{3}$ for NaK $P P$ samples.

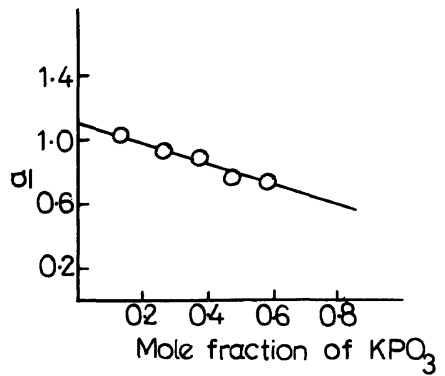

Figure 4. Plot of $a$ against mole fraction of $\mathrm{KPO}_{3}$ for samples of $\operatorname{LiK} P P$.

fraction of $\mathrm{KPO}_{3}$ against the value of ' $a$ ' obtained for both NaKPP as well as LiKPP samples (Figures 3 and 4). In both the cases there is a progressive decrease in the value of ' $a$ ' as the mole fraction of potassium increases. As mentioned earlier the solubility of these samples decreased progressively as the proportion of potassium in the copolymer increased. It is perhaps for the first time that such a result has actually been obtained for copolymers.

Acknowledgement. The authors are grate- ful to the University Grants Commission for financial assistance, CBS was a U.G.C. Research Fellow during the course of investigations and RRS is presently a U.G.C. Research Fellow.

\section{REFERENCES}

1. J. R. Van Wazer, "Phosphorus and its compounds," Vol. I, Interscience, New York, 1958.

2. F. G. R. Gimblett, "Inorganic Polymer Chemistry," Butterworths, London, 1963.

3. N. H. Ray, "Inorganic polymers," Academic Press, New York, N. Y., 1978.

4. U. P. Strauss, E. H. Smith, and P. L. Wineman, J. Am. Chem. Soc., 75, 3935 (1953).

5. H. N. Bhargava, B. K. Varma, and P. K. Agrawal, Colloid Polym. Sci., 256, 252 (1978).

6. K. H. Gustavson and A. Larsson, Acta Chem. Scand., 5, 1221 (1951).

7. A. C. Chatterji and H. N. Bhargava, J. Polym. Sci., 35, 235 (1959).

8. H. N. Bhargava and D. C. Srivastava, J. Phys. Chem., 74, 36 (1970).

9. R. C. Mehrotra and V. S. Gupta, J. Polym. Sci., 54, 613 (1961); ibid., 55, 81 (1.961); ibid., 58, 501 (1962).

10. S. Greenfield and M. Clift, "Analytical Chemistry of the Condensed Phosphates," Pergamon Press, Oxford, New York, N. Y., 1975.

11. D. E. T. Tuan and R. M. Fuoss, J. Phys. Chem., 67, 1343 (1963).

12. C. Tanford, "Physical Chemistry of Macromolecules," John Wiley \& Sons, Inc., New York, N. Y., 1961, Chapter 6.

13. H. Morawetz, "Macromolecules in Solution," Interscience Publishers, New York, N. Y., 1975, Chapter VI.

14. J. H. Bradbury, "Physical Principles of Proteins Chem.," Part II, Sydney Leach, Ed., Academic Press, New York and London, 1970, Chapter 11.

15. C. B. Sharma and H. N. Bhargava, unpublished results.

16. R. R. Srivastava and H. N. Bhargava, unpublished results. 